\title{
Examining Moderators of Vocabulary Acquisition from Kindergarten Through Elementary School Using Local Structural Equation Modeling
}

\author{
Gabriel Olaru $^{1,2}$, Alexander Robitzsch $^{3,4}$, Andrea Hildebrandt $^{5}, \&$ Ulrich Schroeders $^{1}$ \\ ${ }^{1}$ Psychological Assessment, Department of Psychology, University of Kassel, Germany \\ ${ }^{2}$ Developmental Psychology, Tilburg School of Social and Behavioral Sciences, Tilburg \\ University, Netherlands \\ ${ }^{3}$ IPN - Leibniz Institute for Science and Mathematics Education, Kiel, Germany \\ ${ }^{4}$ Centre for International Student Assessment (ZIB), Germany \\ ${ }^{5}$ Psychological Methods and Statistics, Department of Psychology, Carl von Ossietzky \\ Universität Oldenburg, Germany
}

\section{Author Note}

This is a preprint version of a manuscript currently under review.

Correspondence concerning this article should be addressed to:

Gabriel Olaru, Developmental Psychology, Tilburg University, Prof. Cobbenhagenlaan 225, 5037 DB Tilburg, Netherlands, Email: r.g.olaru@tilburguniversity.edu

\section{Funding}

This research was supported by a grant from the Deutsche Forschungsgemeinschaft (DFG) to Ulrich Schroeders and Andrea Hildebrandt (SCHR 1591/1-1 and HI 1780/4-1) as part of the Priority Program 1646 "Education as a Lifelong Process". 


\begin{abstract}
Parental socio-economic status (SES) is often found to be associated with children's language competence in the first decade of life. To examine the effect of SES on children's vocabulary development, as well as a potential compensatory effects of schooling and learning-related activities, we examined the joint and unique effects of parental education, occupational status, and learning environment at home on children's receptive vocabulary competence and growth in early childhood. We used latent growth curve models to distinguish between pre-school receptive vocabulary and growth across primary school. Analyses were based on data from the German National Educational Panel Study (NEPS), a large-scale longitudinal study assessing vocabulary competence and family background from Kindergarten to the $3^{\text {rd }}$ grade of elementary school. To examine the moderating effects of parental education, occupational status, and learning environment at home, we used local structural equation modeling. Results revealed a moderate to strong positive association between parental education and children's receptive vocabulary competence, which fully explained the effect of occupational status on this language skill. With the exception of reading aloud, we found no effect of learning environment at home. Initially lower performing children showed steeper growth trajectories across school, but rank-orders were relatively stable across time. In summary, the results suggest large initial differences in receptive vocabulary between children from different educational backgrounds, which are reduced, but not fully overcome across elementary school.
\end{abstract}

Keywords: Receptive vocabulary; socio-economic status; parental education; learning environment at home; local structural equation modeling 
Language competencies ${ }^{1}$ are arguably the most important cultural competencies we acquire over the course of early childhood. Language is the foundation of all human interactions, a necessity to acquire further knowledge, and a key competence imparted in formal education. However, even before primary education, we find considerable differences among children in language competence and vocabulary knowledge. A substantial share of these differences can be explained by family background variables such as socio-economic status (SES; e.g., 14\% in Haag et al., 2017). SES represents a blend of different facets capturing a person's (or family's) income, wealth, educational level, and occupational status (Conger et al., 2010). SES-associated differences in children's language competence can already be observed in the first years of life (Fernald et al., 2013; Huttenlocher et al., 2010; Roberts et al., 1999). For example, differences in vocabulary between children from different backgrounds remain constant throughout childhood (Farkas \& Beron, 2004; Froiland et al., 2013). Language competence is an important and reliable predictor of school readiness and educational achievement in later years (Burchinal et al., 2002; Hoff, 2013), and in the long run even predicts the SES of the next generation (Sohr-Preston et al., 2013). Therefore, examining and understanding the impact of social and educational background on language acquisition is relevant from the perspective of students, parents, teachers, educational policymakers, and society as a whole.

In this study, we aim to examine the associations between SES and receptive vocabulary competence and growth from nursery school (i.e., at age five; called Kindergarten in the German educational system) through elementary school (i.e., at age nine) in a large representative German panel study. International large-scale studies like PISA suggest that the associations between SES and educational outcomes are particularly strong in Germany (e.g., PISA 2015: $16 \%$ of variance in science performance explained by SES, compared to an

\footnotetext{
${ }^{1}$ For similarities and possible differences between the terms ability, skill, competency, etc. please see Schroeders (2018). In the present study, we use the terms synonymously.
} 
OECD average of 13\%; OECD, 2016). As SES also includes both occupational and educational aspects, we used both an occupation (International Socio-economic Index of Occupational Status; Ganzeboom et al., 1992) and education-based (International Standard Classification of Education; UNESCO Institute for Statistics, 2011) SES measure. In addition, a large number of studies have found that the association of SES on children's language competence can be partly explained through the frequency and quality of parentchild interactions (e.g., time spent on learning-related activities; Conger \& Donnellan, 2007; Lohndorf et al., 2018; Sohr-Preston et al., 2013) and child-directed language usage (Hoff, 2003, 2006; Huttenlocher et al., 2010; Rowe, 2008; Rowe \& Goldin-Meadow, 2009). Therefore, we additionally examine whether the learning environment at home (i.e., the amount and type of activities parents engage in with their children) can explain potential associations between parental SES and children's receptive vocabulary competence and growth, and to what degree it uniquely explains differences in these outcomes. In the following section, we review key findings on the influence of family background variables and schooling on language acquisition in general and vocabulary in particular. Furthermore, we discuss potential transition effects that might drive inter-individual differences among children with different social and educational backgrounds.

\subsection{Socio-economic Status, Learning Environment at Home and Vocabulary Acquisition}

A large body of research has shown that vocabulary acquisition in the first decade of life is positively related to the social and educational background of the family (around 5-17\% of variance explained; e.g., Burchinal et al. 2002; Coddington et al., 2014; Huston et al., 2005; Huttenlocher et al., 2010; Rowe, 2008; Volodina et al., 2020). In a large-scale educational study encompassing a representative sample of about 29,000 German elementary grade students, $14 \%$ of the variance in children's receptive vocabulary in the $4^{\text {th }}$ grade was accounted for by parental SES (Haag et al., 2017). Inter-individual differences in vocabulary can be already observed at early stages of language production, that is, at two to three years of 
age (Arriaga et al., 1998; Dollaghan et al., 1999; Farkas \& Beron, 2004; Huttenlocher et al., 2010). These differences remain relatively stable over the first decade of life when examined longitudinally (Huttenlocher et al., 2010; Farkas \& Beron, 2004). A recent study on academic vocabulary (i.e., technical, scientific, abstract words) competence in a sample of 472 German elementary school students has shown that parental education and the number of books at home explained around $23 \%$ and $25 \%$ of the variance in the initial differences and growth from Grade 2 to 4, suggesting that inter-individual differences in vocabulary competence associated with to the educational background of the family may even increase across school years.

The associations between parental SES and children's educational competencies represent a blend of genetic and environmental effects, and an interaction thereof. Studies examining the heritability of reading comprehension (Hart et al., 2013) or vocabulary intelligence (Rowe et al., 1999) found average heritability estimates of $h^{2}=.67$ and $h^{2}=.57$, respectively. However, the genetic influence was moderated by parental SES, representing a Gene $x$ Environment interaction. The heritability of the cognitive abilities was reported to be larger in families with higher educational or socio-economic levels, for instance ranging from $\mathrm{h}^{2}=.26$ to $\mathrm{h}^{2}=.74$ for low to high SES families (Rowe et al., 1999), suggesting a higher influence of environmental factors on inter-individual differences in lower SES families. The estimated heritability of educational outcomes may represent a blend of the heritability of cognitive abilities and the transmission of other relevant traits, such as personality, selfefficacy or well-being (Kraphohl et al., 2014).

From the perspective of environmental transmission processes, Watermann and Baumert (2006) distinguished between (a) structural characteristics, such as the family's wealth and educational resources, and (b) process characteristics, such as communication and cultural practices within the family. The family investment model (Conger \& Donellan, 2007) suggests that families with higher financial (e.g. income), social (e.g., occupation prestige) 
and human (e.g., education) capital are able to invest these resources in the development of their children, whereas families under economic pressure and lower capital have to use their resources on more immediate needs (Bradley \& Corwyn, 2002). According to these theoretical perspectives, the effect of SES on children's vocabulary skills may explained through learning materials, learning activities, the standard of living, and quality and frequency of child-directed language use (see also Hoff, 2003; Huttenlocher et al., 2010; Rowe, 2008). In line with theoretical assumptions, educational research has supported that higher investment and a more learning-supportive family environment partly mediate the effect of SES on children's receptive vocabulary (Bradley \& Corwyn, 2002; Coddington et al., 2014; Conger \& Donnellan, 2007; Guo \& Harris, 2000; Lohndorf et al., 2018; Lindberg et al., 2020; Sohr-Preston et al., 2013).

Of the different indicators of SES (e.g., income, occupational status, education), parental education seems to be most strongly related to the children's language development (Golinkoff et al., 2019; Weinert \& Ebert, 2013), and in particular maternal education (e.g., Harding et al., 2015; Reardon, 2011). Parental education seems particularly relevant for providing a cognitively stimulating environment (Akukuwe \& Schroeders, 2016; Guo \& Harris, 2000). This effect is directly and indirectly influenced by the provision of a supportive environment that encourages learning (Davis-Kean, 2005; Froiland et al., 2013), but also by the mediating role of higher educational expectations (i.e., parental career aspirations). Parents with more education have been found to provide better learning support for their children (Akukwe \& Schroeders, 2016; Hill \& Taylor, 2004; Hyde et al., 2006)—for example, they offer appropriate homework support (Hoover-Dempsey et al., 2001; Lee \& Bowen, 2006) — and demonstrate more personal involvement and communication (Garg et al., 2002; Lee \& Bowen, 2006).

In summary, SES is a very broad constructs that does not directly transfer to children's vocabulary competence, but can be mediated by the quality and frequency of learning-related 
parent-child interactions. Terms that are often used to characterize such interactions are parental involvement (Hoover-Dempsey \& Sandler, 1995) or the learning environment at home (or home learning environment; McNeal, 1999). The learning environment at home construct encompasses various educationally relevant activities such as playing, reading aloud, providing learning support for the child (e.g., helping with homework), and visiting museums, exhibitions, or historic sites (Lindo, 2014). Some studies suggest that parents with higher SES spend more time on such learning-related activities with their children (Hartas, 2011; Hayes et al., 2016; Tarelli \& Stubbe, 2010). It has been demonstrated that parent-child learning activities positively affect children's language competence and vocabulary knowledge in the first years of primary education (Burchinal et al., 2002; Coddington et al., 2014; Kluczniok \& Mudiappa, 2018; Lohndorf et al., 2018; van Steensel, 2006), pre-school literacy skills (Froiland et al., 2013), and general educational achievement (Castro et al., 2015).

\subsection{Informal and Formal Learning Environments in Germany}

During early childhood, children's cognitive development is primarily guided by the family. Only around one-third of German children below the age of three attended a childcare center in March 2019 (Destatis, 2019). From ages three to five, nearly all German children attend nursery school or some type of childcare center (93\%; Destatis, 2019). Childcare centers in Germany focus especially on social and emotional skills, while academic precursor skills (e.g., phonological awareness, counting, letter knowledge) are rudimentarily taught in the last year prior to schooling (p. 60 ff., ECCE study group, 1999). However, a large share of the cognitive development is placed in the informal family context (Lehrl et al, 2020). In addition, childcare centers typically reflect the demographics of the surrounding area and so may reflect educational disparities attributable to socio-economic differences between neighborhoods (Leventhal \& Brooks-Gunn, 2000). It is a common finding across countries that by the time children enter elementary school, those with a lower socio-economic 
background have more limited language competence and vocabulary compared to children with higher SES background (Alexander et al., 2007; Farkas \& Beron, 2004; Lee \& Burkam 2002; Volodina et al., 2020).

The question arises whether elementary education exerts an equalizing effect for children with different socio-economic backgrounds. Some studies examining the development of language competencies from nursery through primary school have reported compensation effects. For example, Aarnoutse and van Leeuwe (2000) tracked in a longitudinal study the development of different reading abilities (vocabulary, reading comprehension, and spelling) in primary school. The results showed that language abilities for all students are steadily increasing, whereby initial differences are evened out. This might be due to two paradoxical aims of schooling, that is, to "maximize achievement outcomes for all students while minimizing achievement variations among them" (Snow, 1989, p. 871) that are brought into line in everyday school life by focusing on less competent students. Similar compensation effects were reported for different facets of reading skills in several other studies (e.g., Bast \& Reitsma, 1998; Baumert et al., 2012; Rescorla \& Rosenthal, 2004), but not in all (e.g., Cain \& Oakhill, 2011; Luyten \& ten Bruggencate, 2011; Pfost et al., 2012; Volodina et al., 2020). In a comprehensive meta-analysis, Pfost and colleagues (2014) summarized the mixed results finding slightly more studies that reported a compensation effect, but at the same time stressing the large heterogeneity. This heterogeneity has also been reported within single studies finding decreasing differences in educational performance during the school year due to a shared schooling environment, and subsequent increases throughout the summer break due to separate family environments (e.g., Alexander et al., 2007; Downey et al., 2004).

\subsection{The present study}

In this study, we examine receptive vocabulary competence in the last year of nursery school (Kindergarten; i.e., at age five) and its growth across the first three years of elementary 
school (i.e., up to age nine) as a function of parental occupation status, parental education and learning activities at home. Due to the study's longitudinal design at this transitional stage, we investigate effects before and during elementary school. More specifically, we examine whether differences in parental education, occupation, and learning environment at home are associated with a) the initial differences in children's receptive vocabulary competence before the beginning of elementary school, and b) with growth across the first three years of school. With respect to a potential compensatory effect of schooling, we want to examine c) whether potential differences at the beginning of school decrease across the school years.

The majority of studies on the relationships between SES and learning environment at home with children's language acquisition discussed here have examined linear associations between the variables (e.g., linear regressions, mediation analysis). In contrast, the present study complements previous findings by additionally investigating the non-linear relationship of parental education, occupation and learning environment at home with children's receptive vocabulary competence with a recently developed method within the structural equation framework. Specifically, we employ a latent growth curve model (LGCM) to identify individual differences in vocabulary performance in nursery school and growth from nursery school to third grade and use local structural equation modeling (LSEM; Hildebrandt et al., 2009 ; 2016) to study the non-linear moderating effect of parental occupation, parental education, and learning environment at home on the one hand and children's receptive vocabulary competence on the other. We compare these findings to a model in which the covariates are included as linear predictors.

\section{Method}

\subsection{Design and Participants}

Data were collected as part of the National Educational Panel Study (NEPS, Blossfeld et al., 2011), a large-scale study aiming to describe educational processes and trajectories across the entire life span in Germany. The NEPS is a longitudinal multi-cohort study that 
follows six starting cohorts, including newborns, secondary school students, and adults. For this study, we used the Starting Cohort Kindergarten (SC2; doi:10.5157/NEPS:SC2:8.0.1; Blossfeld et al., 2011). Between 2008 and 2013, the data was collected as a part of the Framework Program for the Promotion of Empirical Educational Research funded by the German Federal Ministry of Education and Research (BMBF). Beginning in 2014, NEPS was carried out by the Leibniz Institute for Educational Trajectories (LIfBi) at the University of Bamberg in cooperation with a nationwide network. The data used in this study can be obtained upon request and free of charge at: https://www.neps-data.de/Data-Center/Data-and$\underline{\text { Documentation/Start-Cohort-Kindergarten/105157-NEPSSC2100 }}$

Of the 9,306 German children that participated in the NEPS Starting Cohort Kindergarten, we selected a subsample that participated in the receptive vocabulary test across all three measurement occasions (i.e., nursery school/Kindergarten, first grade, and third grade of elementary school) and provided family background variables on at least one measurement occasion. To link vocabulary scores across measurement occasion, participation in all three was required. This resulted in a final sample size of $N=420$ (204 female) children. The children were on average 5.26 years old $(S D=0.32)$ at the first measurement occasion, 7.26 years old $(S D=0.32)$ at the second occasion, and 9.26 years old $(S D=0.32)$ at the third measurement occasion. German was not the mother tongue of 25 children (6.0\%), 51 children $(12.0 \%)$ had at least one parent born outside Germany, and six children were born outside Germany (1.4\%). A representative survey of elementary school students in Germany (Rjosk et al., 2017) revealed that one-third of elementary school students have a migration background, with $16.8 \%$ being second-generation immigrants (i.e., at least one parent born abroad) and $1.4 \%$ first-generation immigrants. Due to the relatively and absolutely low number of children with a migration background in this NEPS starting cohort and the sample size requirements of the methods applied, we did not include immigration as an additional moderator in our analyses. 


\subsection{Measures}

The data used in this study was collected from 2011 to 2015. Receptive vocabulary was measured in in 2011, 2013 and 2015. The SES measures were updated on a yearly basis. The learning environment at home questionnaire was only administered in 2011, 2012, and 2013.

\subsubsection{Receptive Vocabulary}

Receptive vocabulary refers to the number of words a person is able to comprehend. This competence was assessed at each measurement occasion with a word-level listening comprehension test. In more detail, in an individual testing session, children were asked to select the correct picture out of four response alternatives that best depicted a spoken word. In the NEPS Starting Cohort 2, a German research adaptation (Roßbach et al., 2005) of the Peabody Picture Vocabulary Test (Dunn \& Dunn, 2007) was administered. The items were developed for and tested in the Bildungsprozesse, Kompetenzentwicklung und Selektionsentscheidungen im Vorschul- und Schulalter (BiKS; Weinert et al., 2013) study and European Child Care and Education Study (European Child Care and Education Study Group, 1997). Based on the BiKS sample of 504 children aged 3 years and 10 months to 5 years and 7 months, the items with highest discrimination parameters in an IRT analysis were selected for the first measurement wave of this cohort.

The measure had an anchor test design with partly overlapping items across measurement occasions. That is, non-overlapping items were used to maintain the difficulty of the scale across normal developmental increases in vocabulary, while mutual items were used to link the item properties across measurement occasions in order to create vocabulary competence estimates on a common scale (Kolen \& Brennan, 2004). There were 77 items administered in nursery school, 66 items in first grade, and 71 items in third grade. Of these, 38 linking items were included across the first two measurement occasions, and 48 across the last two, while a total of 23 common items were used in all three occasions. As indicators of 
vocabulary competence, we used WLEs (weighted likelihood estimates, Warm, 1989) derived from a two-parameter item response theory model with linked item difficulty parameters across measurement occasions for the shared items (Haberman, 2009; Kolen \& Brennan, 2004). Reliability estimates for the WLEs ranged from .82 to .86 across the three measurement occasions.

\subsubsection{Socio-Economic Status: Parental Occupational Status}

As an occupation based measure of the family's socio-economic status we used the International Socio-economic Index of Occupational Status (ISEI-88; Ganzeboom et al., 1992; Ganzeboom, 2010), which is based on the income and educational level of different occupations. The ISEI-88 is calculated based on the ISCO-88 occupational classification system by the International Labour Office (1990), which orders occupations on a scale ranging from 16 (e.g., household help/cleaning personnel) to 90 points (e.g., judge). We compared the maternal, paternal and highest ISEI of the two parents (HISEI; Pant et al., 2013; Rjosk et al., 2017) to describe a family’s available socio-economic resources. We averaged the ISEI scores across the five available measurement occasions to attain an indicator of occupation based SES across the four years. In this sample, the average maternal and paternal ISEI values were $50.64(S D=15.05)$ and $50.50(S D=17.99)$, respectively. The family HISEI was $56.52(S D=15.22)$, which is higher than for representative data from Germany in 2016 $(M=50.6 ; S D=20.07 ;$ Rjosk et al., 2017).

\subsubsection{Socio-Economic Status: Parental Education}

As an education based index of parental SES, we used the International Standard Classification of Education (ISCED; UNESCO Institute for Statistics, 2011). The ISCED provides information about educational attainment, comprising information on both the highest school completion certificate and the highest occupational qualification. ISCED in the NEPS studies is represented by 11 categories (in contrast to the original six), capturing the following (German) levels of education: $0=$ No certificate; 1 = Lower general education; 
2 = Intermediate secondary education (Realschulabschluss); 3 = University entrance qualification (Abitur); 4 = Basic vocational training; 5 = Intermediate-level civil servants; 6 = University entrance qualification (adult education); 7 = Basic vocational training (adult education); 8 = Diploma (vocational and other academics; Master's/technician's qualification); 9 = Bachelor's degree, master's degree, university diploma, official professional licensure, highest-level civil servants, and $10=$ Doctorate or postdoctoral qualification (habilitation). We compared the maternal, paternal and the highest ISCED of the two parents (HISCED) as an indicator of the family's educational level. We averaged the scores across the five available measurement occasions for the subsequent analysis. The average maternal, paternal and highest family ISCED values were $5.97(S D=2.45), 6.25(S D$ $=2.53)$, and $6.79(S D=2.37)$, respectively. Of the parents, $36.2 \%$ of mothers and $32.1 \%$ of fathers reported to have basic vocational training, $13.6 \%$ of mothers and $14.0 \%$ of fathers a vocational diploma or technician's qualification, and $23.3 \%$ of mothers and $25.5 \%$ of fathers a bachelor's, master's degree or university diploma.

\subsubsection{Learning Environment at Home}

The learning environment at home (LEH) was measured with a scale developed by Melhuish and colleagues (2008) for the use with pre-school or elementary school children. It comprised eleven items asking parents about the frequency of joint learning-related activities

(e.g., "reading aloud", "painting", "drawing", "doing crafts", "sports", "playing") on an 8-point frequency scale: $1(8)=$ several times a day; $2(7)=$ once a day; $3(6)=$ several times a week; $4(5)=$ once a week; $5(4)=$ several times $a$ month; $6(3)=$ once a month; $7(2)=$ more seldom; $8(1)=$ never (numbers in parentheses represent reverse keyed values which we used for the current analysis). The scale was administered at the household level and filled out by one parent. We reverse-coded the responses so that higher values indicate a higher frequency of learning-related activities. To form a composite LEH score, we computed the mean value across all eleven items within each of the three measurement occasions. Retest correlations 
across one year were $\mathrm{r}=.59$ and $\mathrm{r}=.52(p s<.001)$, respectively, and $\mathrm{r}=.45(p<.001)$ across two years. We used the mean score across all three measurement occasions as an indicator of learning environment at home for the subsequent analysis. On average, parents reported a (reverse) mean LEH of $5.47(S D=0.70)$.

\subsection{Statistical Analysis}

The starting point for our analyses was a latent growth curve model (LGCM, McArdle, 2009) quantifying individual differences in initial vocabulary performance and growth from nursery school to third grade. As the indicators for the factors, we used the linked vocabulary WLEs. We included standardized age as control variables in the model. In the latent growth curve model (see Figure 1), indicator intercepts were constrained to 0 to estimate the latent means of the intercept and slope factors. Loadings on the initial performance (intercept) factor were all constrained to 1, thus capturing stable individual differences in vocabulary competence across measurement occasions. A model in which the factor loadings of the growth (slope) factor were constrained to 0,1 and 2, respectively (i.e., linear growth $)$ did not fit the data well $\left(d f=2 ; \chi^{2}=141.2 ; p<.001 ;\right.$ CFI $=.799 ;$ RMSEA $=$ $.407 ;$ SRMR $=.088)$. We thus freed the third growth factor loading to account for non-linear growth across the three measurement occasions. The model provided good fit to the data $(d f=$ $\left.1 ; \chi^{2}=1.4 ; p=.235 ; \mathrm{CFI}=.999 ; \mathrm{RMSEA}=.031 ; \mathrm{SRMR}=.008\right)$. 


\section{Figure 1}

Latent growth curve model estimated on the full sample

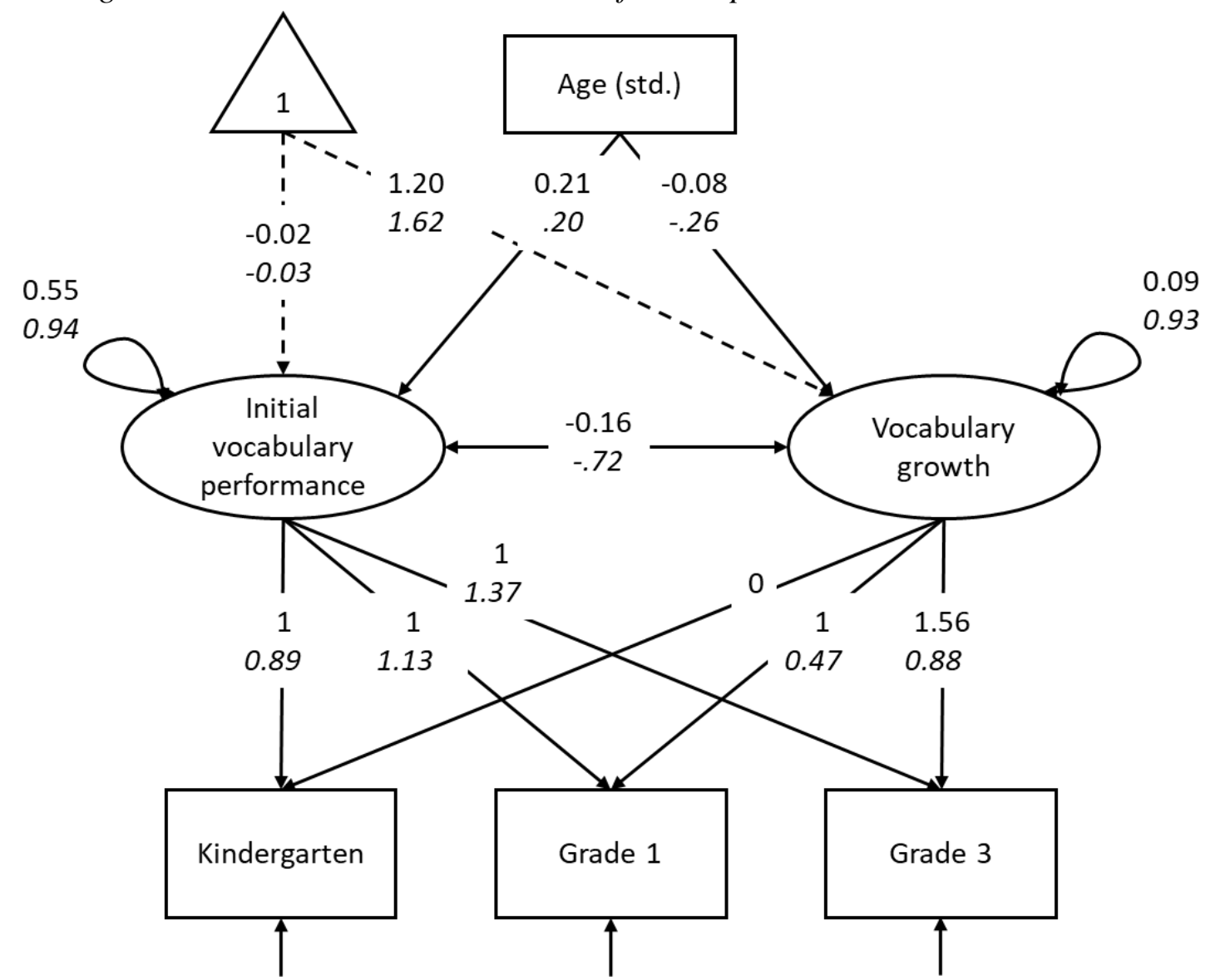

Note. Standardized parameter estimates are displayed in italics below the non-standardized estimates. Indicators of the factors are linked person parameters for receptive vocabulary in nursery school, first grade, and third grade. The triangle refers to the factors' mean estimates. For the growth factor, the mean was standardized by the variance of the performance factor to reflect increases in the metric of initial differences (i.e., standard deviations). $N=420$.

We then used the nonlinear modeling approach of local structural equation modeling (LSEM; Hildebrandt et al., 2009; 2016) to examine moderation effects of parental occupation, education and learning environment at home on the growth curve model described above. LSEM is a newly developed method within the structural equation modeling framework that allows for estimating the LGCM at every potential value of the moderator (e.g., every ISCED level). As such, all model parameters (including factor means, correlations, and variances) can be compared across different levels of the moderators. With sufficient sample size, LSEM allows for the analysis of continuous moderators by weighting observations within a specific range around a focal point of the moderator. More specifically, each observation is weighted according to its distance to a given focal point on the moderator at which the model is 
estimated in a specific step. Focal values are maximally weighted, and weights decrease symmetrically to the left and right as the distance between an observation and the focal point at which the model is being estimated increases. With this procedure, nonlinear effects of the moderator on model parameters can be examined without imposing any restrictions on the shape of the moderation effect (for more details, see Hildebrandt et al., 2016; Olaru, et al., 2019). The LSEM approach goes beyond mean-level differences across the moderators (as are typically addressed in the literature) by permitting the examination of moderation effects on the variance of vocabulary acquisition and the covariance between level and growth of vocabulary. As such, investigations utilizing LSEM provide far more insight into the moderators' effects on different types of longitudinal change, such as absolute, structural, and differential change or stability (for a discussion of different types of change, see Allemand et al., 2007; Caspi \& Roberts, 2001). We apply a permutation-based procedure to test the statistical significance of the nonlinear moderation effects (Hildebrandt et al., 2016; Hülür et al., 2011; Jorgensen, et al., 2018). Unless otherwise stated, all moderation effects reported in the results section were significant $(p<.001)$.

Analyses were conducted in the R Software for Statistical Computing (version 3.4.2; R Core Team, 2018). We used the psych package (Revelle, 2020) for descriptive statistics and correlations, the TAM package (Robitzsch, et al., 2019) to obtain and link item response theory parameters across measurement occasions and calculate WLEs for each participant, and the lavaan package (Rosseel, 2012) to estimate structural equation models. To test for nonlinear associations between the latent parameters of the growth curve model and parental occupation, education, and learning environment at home, we used the functions lsem.estimate and lsem.permutationTest as implemented in the sirt package (Robitzsch, 2019). All analysis scripts and supplementary tables are available in an Open Science Foundation (OSF) repository: https://osf.io/x84fw/?view_only=c814bfad99e5489c8c957368cea26306. 


\section{Results}

\subsection{Descriptive Statistics and Correlations}

Table 1 summarizes descriptive statistics and correlations for vocabulary scores (i.e., WLEs linked across measurement occasions) and all background variables used in this study. In general, there was a strong increase in receptive vocabulary, with Cohen's $d=1.22$ and $d=$ 0.96 between the first and second and second and third measurement occasions, respectively. Receptive vocabulary scores were strongly correlated across measurement occasions $(r=.64$ to .76), indicating a stable rank order in vocabulary over time. However, the variance of vocabulary scores decreased over time from $\sigma^{2}=0.74$ to 0.45 and 0.31 at the first, second and third measurement occasion, respectively $(1$ vs. $2: F(419)=1.63 ; 2$ vs. $3: F(419)=1.44 ; p s<$ $.001)$. Even though the rank order remained stable, the differences between low and high performing children decreased over time. Maternal and paternal indicators of education (ISCED) and occupation (ISEI) both correlated highly with the corresponding highest index for the family (i.e., HISEI; HISCED), with an average $r=.80$. The average correlation between vocabulary scores and highest parental, maternal and paternal occupation based SES indicator (i.e., ISEI) amounted to $\mathrm{r}=.27, .22$ and .21 , respectively. For the education based SES index, the average correlations were $r=.32, .33$ and .28 , respectively. Because of the small differences, we used the highest family indicator for the subsequent analyses. The correlation between parental occupation (i.e., HISEI) and education (i.e., HISCED) amounted to $r=.63(p<.001)$, showing considerable overlap between the two indicators. The LEH composite was unrelated to parental education and SES as well as children's vocabulary knowledge. 


\section{Table 1}

Descriptive Statistics and Correlations of Variables Used in This Study

\begin{tabular}{|c|c|c|c|c|c|c|c|c|c|c|c|c|c|c|c|}
\hline Variable & $M$ & $S D$ & Min & Max & 1 & 2 & 3 & 4 & 5 & 6 & 7 & 8 & 9 & 10 & 11 \\
\hline 1. WLE 1 & -0.02 & 0.86 & -3.69 & 2.22 & & & & & & & & & & & \\
\hline 2. WLE 2 & 1.17 & 0.67 & -1.11 & 3.09 & $.70 * * *$ & & & & & & & & & & \\
\hline 3. WLE 3 & 1.85 & 0.56 & 0.16 & 3.42 & $.64 * * *$ & $.76 * * *$ & & & & & & & & & \\
\hline $\begin{array}{l}\text { 4. highest } \\
\text { occupation }\end{array}$ & 56.52 & 15.22 & 16 & 90 & $.24 * * *$ & $.31 * * *$ & $.25 * * *$ & & & & & & & & \\
\hline $\begin{array}{l}\text { 5. mother } \\
\text { occupation }\end{array}$ & 50.64 & 15.05 & 16 & 90 & $.17 * * *$ & $.28 * * *$ & $.21 * * *$ & $.76^{* * * *}$ & & & & & & & \\
\hline $\begin{array}{l}\text { 6. father } \\
\text { occupation }\end{array}$ & 50.50 & 17.99 & 19 & 88 & $.20 * * *$ & $.25^{* * *}$ & $.18^{* * *}$ & $.81 * * *$ & $.41 * * *$ & & & & & & \\
\hline $\begin{array}{l}\text { 7. highest } \\
\text { education }\end{array}$ & 6.79 & 2.37 & 1 & 10 & $.32 * * *$ & $.36^{* * *}$ & $.27 * * *$ & $.63 * * *$ & $.50 * * *$ & $.55^{* * * *}$ & & & & & \\
\hline $\begin{array}{l}\text { 8. mother } \\
\text { education }\end{array}$ & 5.97 & 2.45 & 0 & 10 & $.33 * * *$ & $.37 * * *$ & $.29 * * *$ & $.55 * * *$ & $.55^{* * * *}$ & $.41 * * *$ & $.8 * * *$ & & & & \\
\hline $\begin{array}{l}\text { 9. father } \\
\text { education }\end{array}$ & 6.25 & 2.53 & 1 & 10 & $.30 * * *$ & $.33 * * *$ & $.21 * * *$ & $.6^{* * *}$ & $.42 * * *$ & $.63 * * *$ & $.84 * * *$ & $.55^{* * * *}$ & & & \\
\hline 10. LEH & 5.47 & 0.7 & 3.5 & 7.18 & .01 & .04 & .02 & -.04 & -.02 & -.05 & .01 & -.05 & -.01 & & \\
\hline 11. Age & 5.32 & 0.34 & 4.46 & 7.29 & $.24 * * *$ & $.14 * *$ & $.13 * *$ & $-.1 *$ & $-.1 *$ & -.09 & -.07 & -.04 & -.07 & -.03 & \\
\hline 12. Gender (f) & $\mathrm{m}=213$ & $f=204$ & & & -.06 & .03 & -.02 & .03 & .06 & .06 & .00 & .02 & .01 & .09 & $-.10 *$ \\
\hline
\end{tabular}

Note. WLE = Linked weighted likelihood estimates of receptive vocabulary from a two-parameter item response theory model; occupation = parental International Socioeconomic Index of Occupational Status (ISEI); education = parental International Standard Classification of Education; highest $=$ highest of both parents; $\mathrm{LEH}=$ Learning environment at home. ${ }^{*}: p<.05 ;{ }^{* *}: p<.01 ;{ }^{* * *}: p<.01$. 


\subsection{Initial Receptive Vocabulary and Growth}

The LGCM indicates nonlinear growth across the three measurement occasions (see Figure 1), with a standardized factor loading of $\lambda=1.56$ at the age of 7 years. The standardized mean of the growth factor was 1.58 (i.e., standardized by the standard deviation of the initial performance factor), indicating that receptive vocabulary competence increased by over one and a half standard deviations between nursery school and first grade and close to one standard deviation between first and third grade. The growth in receptive vocabulary was negatively correlated with baseline performance $(r=-.67 ; \mathrm{p}<.001)$, suggesting that initially lower-performing children experience stronger gains in vocabulary compared to initially better-performing children. Despite this steeper growth among lower-performing children, the inter-individual variance in the growth factor was small compared to the variance of the initial performance factor $\left(\sigma^{2}\right.$ Growth $=0.09 ; \sigma^{2}$ Performance $\left.=0.55\right)$. This illustrates that inter-individual differences in receptive vocabulary competence decrease across the course of the assessment, but the rank order remains relatively stable (see also Table 1).

\subsection{Linear Relationships Between Receptive Vocabulary and Background Variables}

We included parental occupation, education, learning environment at home, and children's age (control variable) as linear predictors of initial vocabulary performance and growth. We also modeled the indirect effects of parental education through occupation and learning environment at home as well as the indirect effects of occupation and education through learning environment at home. The regression parameter estimates can be found in Table 2 (for models based on maternal and paternal education, please see OSF Table 1). Apart from children's age, parental education was the only significant predictor of vocabulary performance (standardized $\beta=.35 ; p=.001$ ) and growth (standardized $\beta=-.35 ; p=.009$ ). Most notably, occupation had no substantial association with initial receptive vocabulary performance and growth when education was included as an additional covariate (compare to the zero-order correlations in Table 1). Instead, the relation between SES and children's 
language competence can be mostly explained by the educational aspects of SES (occupation predicted by education: standardized $\beta=.62 ; p<.001)$. Parental education had a moderate positive relationship with children's initial receptive vocabulary, but it was also associated with lower growth. This can be explained by the large negative correlation between performance and growth (i.e. initially better performing children increasing less on the receptive vocabulary scores). Nevertheless, the unstandardized regression weight of parental education on children's vocabulary growth (unstandardized B $=-0.04$ ) was relatively small compared to the positive weight on initial vocabulary performance (unstandardized B $=0.11$ ). As both factors are represented on the same metric, this suggests that the initial differences are partly maintained across the four years, which is also supported by the high rank-order stability ( $r=.64$ to .76$)$ of receptive vocabulary scores across measurement occasions (see Table 1). 
Table 2.

Linear Associations Between Family Background and Receptive Vocabulary Performance and Growth

\begin{tabular}{llcccc}
\hline Outcome & Predictor & Estimate & CI 95\% & $p$-value & Std. estimate \\
\hline Parental occupation (HISEI) & Parental education (HISCED) & 4.025 & {$[3.545 ; 4.505]$} & .000 & .626 \\
\hline Learning Environment Home & Parental education (HISCED) & 0.017 & {$[-0.018 ; 0.052]$} & .344 & .059 \\
& Parental occupation (HISEI) & -0.004 & {$[-0.010 ; 0.002]$} & .213 & -.078 \\
\hline RV Performance & Parental education (HISCED) & 0.109 & {$[0.070 ; 0.148]$} & .000 & .346 \\
& Parental occupation (HISEI) & 0.006 & {$[0.000 ; 0.012]$} & .075 & .114 \\
& Learning Environment Home & 0.028 & {$[-0.076 ; 0.132]$} & .601 & .026 \\
& Standardized age & 0.647 & {$[0.431 ; 0.863]$} & .000 & .294 \\
\hline RV Growth & Parental education (HISCED) & -0.041 & {$[-0.063 ;-0.019]$} & .000 & -.353 \\
& Parental occupation (HISEI) & 0.000 & {$[-0.004 ; 0.004]$} & .790 & .024 \\
& Learning Environment Home & -0.001 & {$[-0.056 ; 0.054]$} & .971 & -.003 \\
& Standardized age & -0.257 & {$[-0.371 ;-0.143]$} & .000 & -.315 \\
\hline
\end{tabular}

Note. CI 95\% = 95\% confidence intervals; $\mathrm{p}$-value $=$ significance value; RV = children's receptive vocabulary; Parental occupation $($ HISEI $)=$ highest parental International Socioeconomic Index of Occupational Status; Parental education (HISCED) = highest parental International Standard Classification of Education. 


\subsection{Nonlinear Relationships Between Vocabulary Acquisition and Background}

\section{Variables}

The regression model only examined linear relationships between the background variables and initial performance and growth in receptive vocabulary. To overcome this limitation, we used LSEM to study nonlinear moderating effects on all model parameters. Figure 2 illustrates the effect of parental occupation, education, and learning environment at home on initial receptive vocabulary performance and growth. Overall, initial vocabulary competence increased across the education and occupation, but not the learning environment at home composite used in this study. The increase was not perfectly linear, but only occurred for below-average parental education (i.e., up to a HISCED = 7) and occupation (i.e., up to a HISEI = 50). This suggests that differences in educational and occupational background are more strongly related to differences in receptive vocabulary competence in the lower spectrum of these variables. Children from parents with lower educational qualifications or less prestigious occupations families had lower scores compared to their peers from average to highly educated families, with a strong absolute standardized effect size of about $d=0.80$ and 0.85 across the examined range of educational and occupational levels, respectively. In contrast, the linear approximation only suggested a moderate effect size due to the actual underlying curvilinear pattern (see Figure 2). Children from less educated families also showed higher growth in the receptive vocabulary over the course of elementary school. However, compared to the initial differences, differences in growth were small (e.g., an absolute effect size of $d=0.24$ and 0.25 across the examined educational and occupational levels, respectively). This may also represent a ceiling effect in the initial measurement of receptive vocabulary competence, as the test administered on the first measurement occasion was comparatively easy (i.e., a median of $71 \%$ and maximum of $94 \%$ correctly solved items at the first measurement occasion). 


\section{Figure 2}

Standardized Factor Means of Performance and Growth Factor in Receptive Vocabulary Competence Across Parental Education, Occupation and Learning Environment at Home

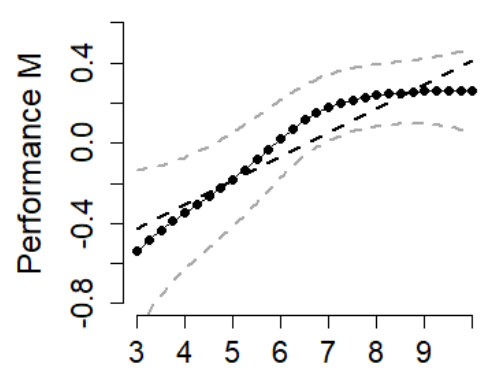

Parental education (HISCED)

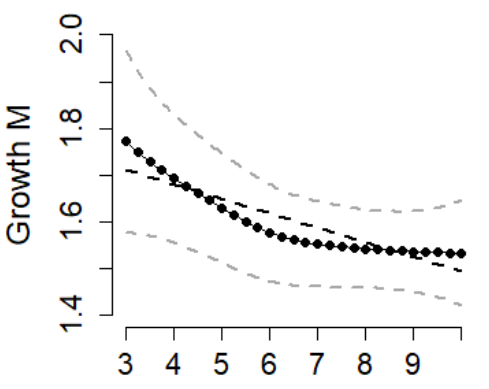

Parental education (HISCED)

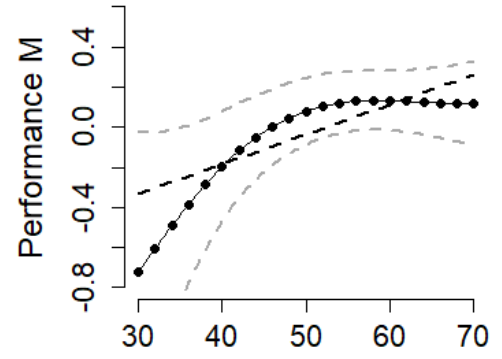

Parental occupation (HISEI)

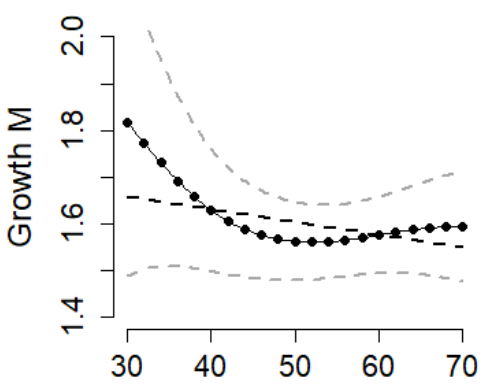

Parental occupation (HISEI)

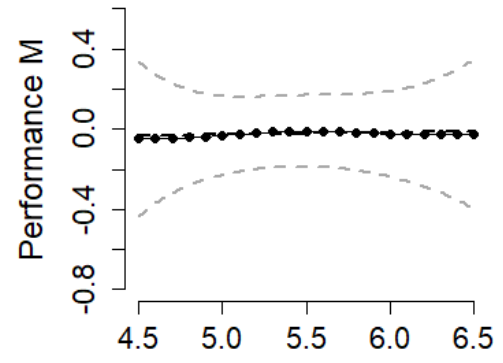

Learning Environment Home

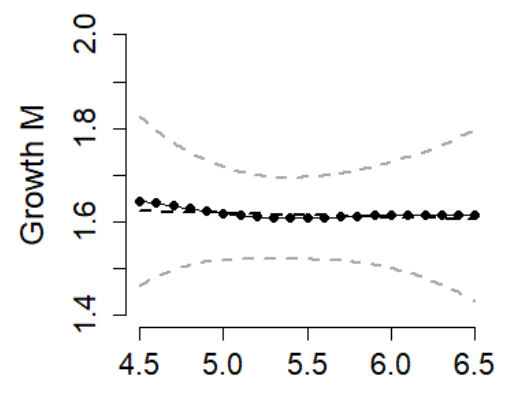

Learning Environment Home

Note. The dark dots represent point estimates at focal moderator values. The dashed black line depicts the linear approximation. Dashed grey lines represent the $95 \%$ confidence interval for each point estimate.

\subsection{The Unique Effect of Parental Occupational Status}

Because the association between occupational status and receptive vocabulary was attenuated when accounting for shared variance with education in the regression approach, we also wanted to examine whether occupational status would be a significant moderator in LSEM after controlling for education. To do so, we removed the education-related variance in the occupational status index by partialing out the HISCED from the HISEI (according to the rationale that education is an antecedent of occupation). Education (i.e., HISCED) explained about $39 \%$ of the variance in occupational status (i.e., HISEI). Conversely, $61 \%$ of interindividual differences in occupational socio-economic status could not explained by 
education. Nonetheless, the LSEM analyses with residualized occupational status as a moderator demonstrated that the association with vocabulary competence disappeared when correcting for educational aspects (Figure 3), supporting our previous findings with the regression based approach.

\section{Figure 3}

Standardized Means of the Performance and Growth Factors Across Parental Occupation Status Controlled for Parental Education
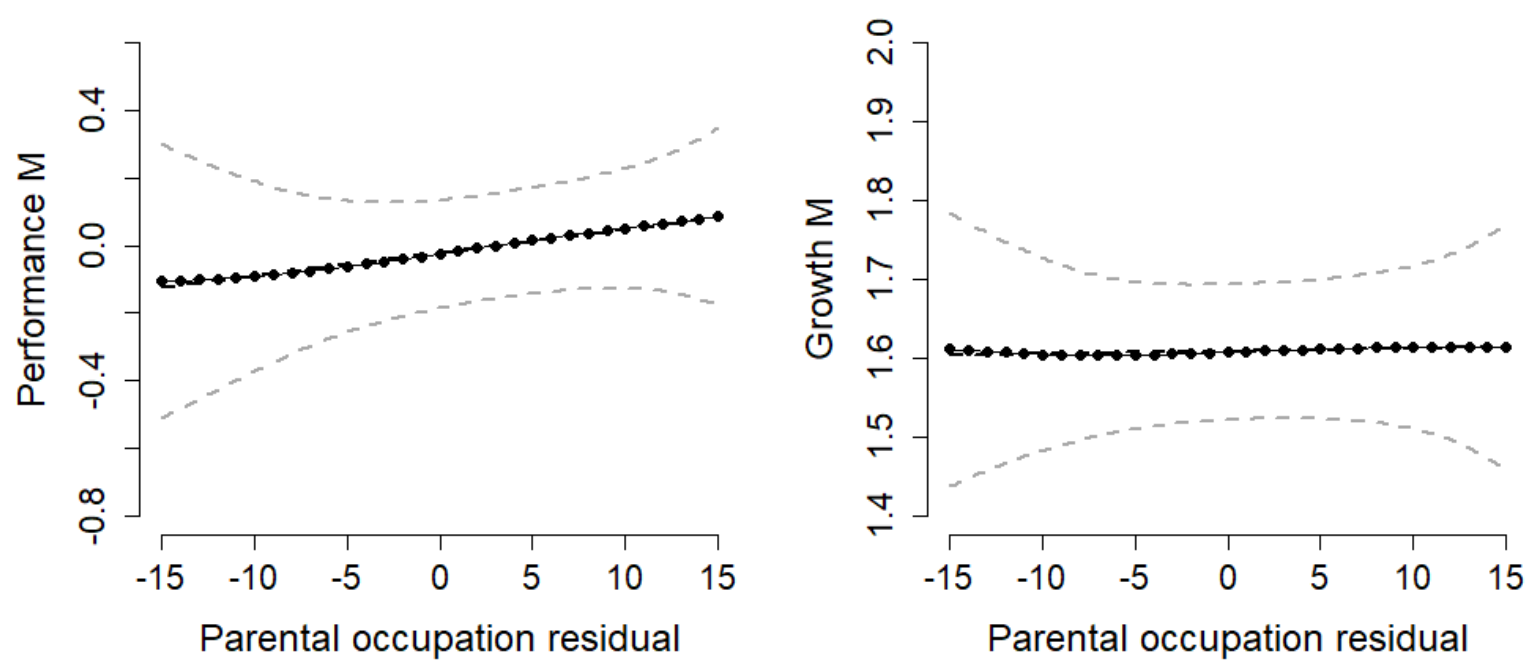

Note. Dots represent point estimates at each moderator level. The dashed black line shows the linear approximation. Dashed grey lines represent the 95\% confidence interval for each point estimate. Parental occupation residual $=$ Residual of the regression explaining HISEI by HISCED.

\subsection{Exploratory Analyses}

\subsubsection{Learning Environment at Home}

Contrary to expectations, we did not find a significant association between the Learning Environment at Home and children's receptive vocabulary skills. One potential 
reason is that the measure was too broad and heterogeneous, masking potential associations of single activities relevant to vocabulary development. We thus added all eleven LEH activities as covariates of the vocabulary performance and growth factors (Figure 1), controlling for age, parental education (HISCED) and occupation (HISEI). The associations are presented in Table 3. Of all activities measured in the questionnaire, only reading aloud had a significant positive association with the receptive vocabulary performance factor (standardized $\beta=.22 ; p$ $=.001$ ). All activity items correlated positively amongst each other (average $r=.20$;

Cronbach's $\alpha=.72$; for correlations see OSF Table 2).

Table 3.

Learning Environment at Home Activities as Predictors of Receptive Vocabulary

Performance and Growth Factors

\begin{tabular}{lrrrr}
\hline Vocabulary Performance & Estimate & CI 95\% & $p$-value & Std. estimate \\
\hline Parental education & 0.099 & {$[0.056 ; 0.142]$} & .000 & .325 \\
Parental occupation & 0.003 & {$[-0.003 ; 0.009]$} & .394 & .062 \\
Standardized age & 0.521 & {$[0.300 ; 0.742]$} & .000 & .253 \\
\hline Activity with letters & 0.014 & {$[-0.055 ; 0.083]$} & .686 & .027 \\
Activity with numbers & -0.027 & {$[-0.111 ; 0.057]$} & .533 & -.042 \\
Learning poems, rhymes, songs & -0.023 & {$[-0.082 ; 0.036]$} & .439 & -.051 \\
Visit a library & -0.006 & {$[-0.071 ; 0.059]$} & .847 & -.011 \\
Reading aloud & 0.222 & {$[0.095 ; 0.349]$} & .001 & .222 \\
Telling stories & -0.003 & {$[-0.050 ; 0.044]$} & .893 & -.008 \\
Musical activities & 0.021 & {$[-0.030 ; 0.072]$} & .414 & .050 \\
Painting, drawing, doing crafts & 0.021 & {$[-0.055 ; 0.097]$} & .597 & .035 \\
Sport activities & 0.006 & {$[-0.061 ; 0.073]$} & .858 & .011 \\
Playing & -0.093 & {$[-0.181 ;-0.005]$} & .040 & -.134 \\
Playground / park & 0.032 & {$[-0.041 ; 0.105]$} & .380 & .051 \\
& & & & \\
\hline Vocabulary Growth & Estimate & CI 95\% & $p$-value & Std. estimate \\
\hline Parental education & -0.041 & {$[-0.065 ;-0.017]$} & .000 & -.396 \\
Parental occupation & 0.001 & {$[-0.003 ; 0.005]$} & .775 & .032 \\
Standardized age & -0.232 & {$[-0.348 ;-0.116]$} & .000 & -.334 \\
\hline Activity with letters & -0.015 & {$[-0.050 ; 0.020]$} & .424 & -.082 \\
Activity with numbers & -0.007 & {$[-0.050 ; 0.036]$} & .746 & -.034 \\
Learning poems, rhymes, songs & 0.021 & {$[-0.010 ; 0.052]$} & .178 & .138 \\
Visit a library & -0.007 & {$[-0.040 ; 0.026]$} & .684 & -.036 \\
Reading aloud & -0.031 & {$[-0.098 ; 0.036]$} & .363 & -.091 \\
Telling stories & -0.010 & {$[-0.035 ; 0.015]$} & .453 & -.072
\end{tabular}


Musical activities

\begin{tabular}{rrrr}
-0.015 & {$[-0.040 ; 0.010]$} & .280 & -.103 \\
-0.003 & {$[-0.042 ; 0.036]$} & .875 & -.016 \\
-0.006 & {$[-0.041 ; 0.029]$} & .754 & -.030 \\
0.038 & {$[-0.009 ; 0.085]$} & .110 & .161 \\
0.009 & {$[-0.028 ; 0.046]$} & .640 & .042 \\
\hline
\end{tabular}

Painting, drawing, doing crafts

Sport activities

Playing

.640

.042

Note. CI 95\% $=95 \%$ confidence intervals; $p$-value $=$ significance value; $\mathrm{RV}=$ children's receptive vocabulary; Parental occupation $(\mathrm{HISEI})=$ highest parental International Socioeconomic Index of Occupational Status; Parental education (HISCED) = highest parental International Standard Classification of Education.

\subsubsection{Immigration status}

We next examined how immigration status was correlated with the receptive vocabulary scores, parental education and occupation, as well as LEH (see Table 4). With exception of whether the child was born outside Germany, which only applied to six children, all migration variables showed small to moderate negative associations with vocabulary scores, parental occupation and education. The magnitude of the correlations did not depend on whether at least one or both parents were born outside Germany. The mother tongue of the child (non-German: $\mathrm{N}=25$ ) yielded the strongest associations, with an average $\mathrm{r}=-.38$ with the receptive vocabulary scores, $r=-.22$ with parental occupation (HISEI), and $r=-.33$ with parental education (HISCED). 
Table 4.

Frequencies and Correlations Between Immigration Status and Variables Used in This Study

\begin{tabular}{|c|c|c|c|c|c|c|c|c|c|c|c|c|}
\hline $\begin{array}{l}\text { Born outside } \\
\text { Germany }\end{array}$ & no & yes & WLE 1 & WLE 2 & WLE 3 & $\begin{array}{l}\text { Highest } \\
\text { occu. }\end{array}$ & $\begin{array}{l}\text { Mother } \\
\text { occu. }\end{array}$ & $\begin{array}{l}\text { Father } \\
\text { occu. }\end{array}$ & $\begin{array}{l}\text { Highest } \\
\text { education }\end{array}$ & $\begin{array}{l}\text { Mother } \\
\text { education }\end{array}$ & $\begin{array}{l}\text { Father } \\
\text { education }\end{array}$ & LEH \\
\hline Mother & 379 & 38 & $-.33 * * *$ & $-.27 * * *$ & $-.22 * * *$ & $-.19^{* *}$ & $-.17 *$ & -.10 & $-.33 * * *$ & $-.36 * * *$ & $-.27 * * *$ & .06 \\
\hline Father & 360 & 39 & $-.39 * * *$ & $-.30 * * *$ & $-.28 * * *$ & $-.17 *$ & -.09 & -.15 & $-.32 * * *$ & $-.28 * * *$ & $-.34 * * *$ & .12 \\
\hline One parent & 345 & 51 & $-.38 * * *$ & $-.28 * * *$ & $-.24 * * *$ & $-.17 *$ & -.12 & -.13 & $-.32 * * *$ & $-.33 * * *$ & $-.32 * * *$ & .09 \\
\hline Both parents & 373 & 23 & $-.34 * * *$ & $-.28 * * *$ & $-.26 * * *$ & $-.17 *$ & -.12 & -.13 & $-.33 * * *$ & $-.31 * * *$ & $-.30 * * *$ & .10 \\
\hline Child & 414 & 6 & -.12 & -.05 & -.05 & .01 & .05 & .00 & $-.18 * *$ & $-.16^{*}$ & -.15 & .07 \\
\hline $\begin{array}{l}\text { German } \\
\text { second } \\
\text { lanougae }\end{array}$ & 389 & 25 & $-44 * * *$ & $-37 * * *$ & $-34 * * *$ & $-22 * * *$ & -14 & $-19 * *$ & $-33 * * *$ & $-31 * * *$ & $-35 * * *$ & 02 \\
\hline
\end{tabular}

Note. WLE = Linked weighted likelihood estimates of receptive vocabulary from a two-parameter item response theory model; occu. $=$ parental

International Socioeconomic Index of Occupational Status (ISEI); education = parental International Standard Classification of Education; highest

$=$ highest of both parents; LEH = Learning environment at home. ${ }^{*}: p<.05 ;{ }^{* *}: p<.01 ;{ }^{* * * *}: p<.01$. 


\section{Discussion}

In this study, we examined differences in children's receptive vocabulary from Kindergarten throughout elementary school and their association with parental education, occupational status and learning environment at home. We applied latent growth curve modeling to differentiate between initial levels of receptive vocabulary competence at school entrance as well as growth across the examined time range. Furthermore, we compared maternal, paternal and family-level indicators of SES and studied linear and non-linear associations in a structural equation modeling context.

Our first research question was whether initial differences in receptive vocabulary competence were associated with parental education, occupation and learning environment at home. we found that the highest parental educational index explained around $12.0 \%$ of the variance in receptive vocabulary skills, which is similar to previous findings on the association between vocabulary and SES (Burchinal et al. 2002; Coddington et al., 2014; Huston et al., 2005; Huttenlocher et al., 2010; Rowe, 2008; Volodina et al., 2020). The explained variance was slightly smaller for maternal (11.0\%; see OSF Table 1$)$ than paternal education (8.6\%), supporting the notion that maternal education is particularly relevant (Harding et al., 2015; Reardon, 2011). However, the slightly larger explained variance $(12.0 \%)$ of the highest parental index suggests that it may provide a more adequate representation of the family's educational capital. One of the central finding of this study is that parental education fully explained the relationship between the occupation-based SES indicator and children's receptive vocabulary competence from nursery school to third grade. This suggests that the human capital (Conger \& Donellan, 2007) of a family is particularly relevant for children's receptive vocabulary development. At this point, we should mention that we do not know which environmental or hereditary factors within the family are responsible for the found effects. Potential transmission processes of parental education on children's vocabulary development may be, among others, the complexity of language used 
when communicating with the child (Huttenlocher et al., 2010), the quality of cognitively stimulating activities (Harding et al., 2015) and the heritability of cognitive abilities or other traits relevant to learning (Kraphohl et al., 2014). The non-linear analysis has shown a strong difference in children's receptive vocabulary competence at the beginning of school in the lower spectrum of educational background, whereas we found no between families with an advanced degree (e.g., vocational diploma, master's/technician's qualification, university degree, high-level civil servants, doctorate). Interventions aimed at increasing parental education (e.g., Gennetian et al., 2008) may thus provide the strongest benefit for families with particularly low educational levels.

Contrary to previous studies, we did not find an association between learning environment at home and parental education or children's receptive vocabulary competence (Coddington et al., 2014; Kluczniok, \& Mudiappa, 2018; Lohndorf et al., 2018; Lindberg et al., 2020; Melhuish et al., 2008; Weinert \& Ebert, 2013). We found that only the activity of reading aloud was related to initial differences, explaining around $4.9 \%$ of the differences after controlling for parental education. The number of books in the household has been shown to explain the variance in academic vocabulary competence in elementary school children beyond the parental education alone (books: 20\%; parental education: 17\%; Volodina et al., 2020), and reading books together has been reported to facilitate vocabulary acquisition and early literacy skills (Scarborough \& Dobrich 1994; Ewers \& Brownson 1999; Sénéchal, 2006). Reading together thus seems to provide a compensatory mechanism to reduce disparities at the beginning of elementary school. Potential reasons for the smaller effect sized in our study might be that the self-report frequency scales did not differentiate well across the actual underlying differences in the amount and in particular the quality of these activities. The positive correlations among all indicators may suggest a general engagement level in parent-child activities, but also inter-individual differences in the usage of the response scale. 
A more objective measurement of LEH is needed in future replications to potentially identify more pronounced effects.

Our second and third research question were whether the growth in children's receptive vocabulary is associated with the family background, and whether initial differences in receptive vocabulary decreased across schools. The negative correlation between initial levels and growth, as well as the decreasing variance in the vocabulary scores across time, support the notion that school provides an equalizing effect on children's receptive vocabulary (see also, Pfost et al., 2014). The negative association between parental education and growth also shows that the initial differences due to educational background also decreased across elementary school. Arguably, children with initially lower receptive vocabulary competence profit most from the schooling environment.

In contrast to elementary school, attending nursery school (Kindergarten) is not compulsory in Germany, and inter-individual differences due to family background were particularly large at the beginning of elementary school. The German tracked school system has a relative early separation of ability groups into different school paths (i.e., starting in Grade 5), which may further increase the initial differences in educational outcomes. Elementary school is thus particularly relevant for the educational trajectory of students in Germany. However, even though we found that the differences in vocabulary competence decreased during the first years of school, the rank-order stability remained high, and differences in growth were smaller than initial differences. The unstandardized effect of parental education on initial differences was also more than twice as high as the negative effect on growth, suggesting that schooling may to reduce initial differences in receptive vocabulary among children of different educational backgrounds, but not fully overcome them. Informal learning outside of school after school or during the summer break (see also Alexander et al., 2007; Downey et al., 2004) may be one reason of why these initial differences are maintained. 


\subsection{Limitations and Future Research}

The first limitation of this study was the exclusive reliance on receptive vocabulary as the sole indicator of vocabulary competence. Moreover, the vocabulary measure for the first measurement occasion was relatively easy. This skewed measurement of receptive vocabulary competence may have contaminated estimates of the true effect size, or actual differences in receptive vocabulary skills within the higher spectrum of parental education might not have been captured by the administered test. Additional measures of vocabulary or language competence, such as expressive vocabulary, would also have been desirable, but were not available in the analyzed panel data.

Our second limitation refers to the covariates used in this study. The measure of the learning environment at home was both highly subjective due to the self-reported nature of the assessment and limited with respect to language-related activities. Similarly, the other moderators used in this study (i.e., ISEI and ISCED) only provide approximation of the true underlying differences in human (i.e., education), social (i.e., occupational prestige) and financial (i.e., income, wealth) capital between families. These measures are no causal entities in themselves, but are related to the processes that drive the found associations between SES and receptive vocabulary instead. We thus examined the associations with children's receptive vocabulary at a descriptive level, but further research is needed to uncover the processes through which parental education affects this outcome (e.g. Conger et al., 2010; Harding et al., 2015). The occupational status index (ISEI-88) available in the dataset at the time of the analysis was also based on the occupational status of the professions in 1988 (Ganzeboom \& Treiman, 1996), and might have provided an outdated evaluation of occupational status. Furthermore, we did not include household income as an indicator of financial capital because it was only assessed at the first measurement occasion and only available for 335 participants. A sensitivity analysis in which income was additionally added 
as a covariate of the receptive vocabulary performance and growth factor yielded no significant association beyond the covariates used in this study (see OSF Table 3).

Third, due to a lack of three measures of vocabulary skills for the majority of the panel study sample, the overall sample size used in this study was comparatively small. This was in particular problematic with respect to a low number of children with immigration background. In our sample, 25 of children did not speak German as their first language, and 51 children had at least one parent born outside Germany. Accordingly, we were not able to incorporate migration background as an additional moderator into our analysis. Our additional analyses have shown that immigration status was related to both receptive vocabulary competence and parental education and occupational status, providing a partial explanation for the found association between receptive vocabulary and educational background at the overall sample level. Reading interventions developed specifically for second-language learners (e.g. Chen et al., 2018) may help reduce these differences in vocabulary competence. A replication examining whether the association between parental education and vocabulary competence is similar within the group of children with and the group without immigration background is required to further understand the role of parental education in children's language development. Within the group of children with immigration status, several additional moderators are relevant for the vocabulary development of the children, such as the language spoken at home, the time when parents or children moved to Germany, or the time children learned German as a secondary language.

\subsection{Conclusion}

In this study, we investigated the linear and nonlinear relationships between parental education, occupational status and learning environment at home with children's receptive vocabulary over the first years of education in Germany. Differences in parental education were moderately (linear effect) to strongly (non-linear effect) associated with children's receptive vocabulary at the start of school. Similar effects were found for parental 
occupational status, but the associations vanished after controlling for parental education. Initial differences in children's receptive vocabulary decreased over the course of elementary school, but rank-orders remained relatively stable across time. With the exceptions of the small effect size of reading aloud, we found no effect of learning environment at home on children's receptive vocabulary, which might be attributed to issues in the measurement of this variable.

\section{References}

Aarnoutse, C., \& van Leeuwe, J. (2000). Development of poor and better readers during the elementary school. Educational Research and Evaluation, 6, 251-278. https://doi.org/10.1076/1380-3611(200009)6:3;1-A;FT251.

Akukwe, B. \& Schroeders, U. (2016). Socio-economic, cultural, social, and cognitive aspects of family background and the biology competency of ninth-graders in Germany. Learning and Individual Differences, 45, 185-192. https://doi.org/10.1016/j.lindif.2015.12.009

Alexander, K. L., Entwisle, D. R., \& Olson, L. S. (2007). Lasting consequences of the summer learning gap. American Sociological Review, 72, 167-180. https://doi.org/10.1177/000312240707200202

Allemand, M., Zimprich, D., \& Hertzog, C. (2007). Cross-sectional age differences and longitudinal age changes of personality in middle adulthood and old age. Journal of Personality, 75, 323-358. https://doi.org/10.1111/j.1467-6494.2006.00441.x

Arriaga, R., Fenson, L., Cronan, T., \& Pethick, S. (1998). Scores on the MacArthur Communicative Development Inventory of children from low and middle-income families. Applied Psycholinguistics, 19, 209-223.

https://doi.org/10.1017/S0142716400010043 
Bast, J., \& Reitsma, P. (1998). Analyzing the development of individual differences in terms of Matthew effects in reading: Results from a Dutch longitudinal study. Developmental Psychology, 34, 1373-1399. https://doi.org/10.1037/0012-1649.34.6.1373

Baumert, J., Nagy, G., \& Lehmann, R. (2012). Cumulative advantages and the emergence of social and ethnic inequality: Matthew effects in reading and mathematics development within elementary Schools? Child Development, 83(4), 1347-1367. https://doi.org/10.1111/j.1467-8624.2012.01779.x

Blossfeld, H.-P., Rossbach, H.-G., \& von Maurice, J. (Eds.). (2011). Zeitschrift für Erziehungswissenschaft (Special Issue 14): Education as a Lifelong Process. The German National Educational Panel Study (NEPS). Wiesbaden, Germany: VS Verlag für Sozialwissenschaften.

Bradley, R. H., Caldwell, B. M., \& Corwyn, R. F. (2003). The child care HOME inventories: Assessing the quality of family child care homes. Early Childhood Research Quarterly, 18, 294-309. https://doi.org/10.1016/S0885-2006(03)00041-3

Bradley, R. H., \& Corwyn, R. F. (2002). Socioeconomic status and child development. Annual Review of Psychology, 53, 371-399. https://doi.org/10.1146/annurev.psych.53.100901.135233

Bradley, R. H., Corwyn, R. F., McAdoo, H. P., \& García Coll, C. (2001). The home environments of children in the United States part I: Variations by age, ethnicity, and poverty status. Child Development, 72: 1844-1867. https://doi.org/10.1111/1467$\underline{8624 . t 01-1-00382}$

Bradley, R. H., \& Corwyn, R. F. (2002). Socioeconomic status and child development. Annual Review of Psychology, 2002(53), 371-399. https://doi.org/10.1146/annurev.psych.53.100901.135233

Burchinal, M. R., Peisner-Feinberg, E., Pianta, R., \& Howes, C. (2002). Development of academic skills from preschool through second grade: family and classroom Predictors of 
developmental trajectories. Journal of School Psychology, 40, 415-436. https://doi.org/10.1016/S0022-4405(02)00107-3

Burkam, D. T., Ready, D. D., Lee, V. E., \& LoGerfo, L. F. (2004). Social-class differences in summer learning between nursery school and first grade: Model specification and estimation. Sociology of Education, 77, 1-31. https://doi.org/10.1177/003804070407700101

Cain, K., \& Oakhill, J. (2011). Matthew-effects in young readers: Reading comprehension and reading experience aid vocabulary development. Journal of Learning Disabilities, 44, 431-443. https://doi.org/10.1177/0022219411410042

Caspi, A., \& Roberts, B. W. (2001). Personality development across the life course: The argument for change and continuity. Psychological Inquiry, 12, 49-66. https://doi.org/10.1207/S15327965PLI1202_01

Castro, M., Expósito-Casas, E., López-Martín, E., Lizasoain, L., Navarro-Asencio, E., \& Gaviria, J. L. (2015). Parental involvement on student academic achievement: A metaanalysis. Educational Research Review, 14, 33-46. https://doi.org/10.1016/j.edurev.2015.01.002

Coddington, C. H., Mistry, R. S., \& Bailey, A. L. (2014). Socioeconomic status and receptive vocabulary development: Replication of the parental investment model with Chilean preschoolers and their families. Early Childhood Research Quarterly, 29, 538-549. https://doi.org/10.1016/j.ecresq.2014.06.004

Conger, R. D., \& Donnellan, M. B. (2007). An interactionist perspective on the socioeconomic context of human development. Annual Review of Psychology, 58, 175199. https://doi.org/10.1146/annurev.psych.58.110405.085551

Chen, S., Lawrence, J. F., Zhou, J., Min, L., \& Snow, C. E. (2018). The efficacy of a schoolbased book-reading intervention on vocabulary development of young Uyghur children: 
A randomized controlled trial. Early Childhood Research Quarterly, 44, 206 -219. http://dx.doi.org/10 .1016/j.ecresq.2017.12.008

Davis-Kean, P. E. (2005). The influence of parent education and family income on child achievement: The indirect role of parental expectations and the home environment. Journal of Family Psychology, 19, 294-304. https://doi.org/10.1037/0893-3200.19.2.294

Destatis (2019). Kindertagesbetreuung unter Dreijährirger im März 2019: +3,7 Prozent gegenüber dem Vorjahr [Child day care under three year olds in March 2019: +3.7 percent compared to the previous year]. Retrieved from https://www.destatis.de/DE/Presse/Pressemitteilungen/2019/09/PD19_379_225.html;jses sionid=FCAE3CCFA3459F9D931DD909A036B06D.internet742

Dollaghan, C. A., Campbell, T. F., Paradise, J. L., Feldman, H. M., Janosky, J. E., Pitcairn, D. N., \& Kurs-Lasky, M. (1999). Maternal education and measures of early speech and language. Journal of Speech, Language, and Hearing Research, 42, 1432-1443. https://doi.org/10.1044/jslhr.4206.1432

Downey, D. B., von Hippel, P. T., \& Broh, B. A. (2004). Are schools the great equalizer? Cognitive inequality during the summer months and the school year. American Sociological Review, 69, 613-635. https://doi.org/10.1177/000312240406900501

Duncan, G. J., Brooks-Gunn, J., \& Klebanov, P. K. (1994). Economic deprivation and early childhood development. Child Development, 65, 296-318. https://doi.org/10.1111/j.14678624.1994.tb00752.x

Dunn, L. M., \& Dunn, D. M. (2007). Peabody picture vocabulary test (4th ed.). San Antonio: Pearson.

European Child Care and Education-Study Group (1997). European Child Care and Education Study: Cross National Analyses of the quality and effects of early childhood programmes on children's development. RTD Action: Targeted Socio-Economic Research. 
European Child Care and Education-Study Group (1999). Study Group: School-age assessment of child development: Long-term impact of pre -school experiences on school success, and family-school relationships. Report submitted to European Union DG XII: Science, Research and Development. RTD Action: Targeted Socio-Economic Research.

Ewers, C. A., \& Brownson, S. M. (1999). Kindergarteners vocabulary acquisition as a function of active vs. passive storybook reading, prior vocabulary and working memory. Reading Psychology, 20, 11-20. https://doi.org/10.1080/027027199278484

Farkas, G., \& Beron, K. (2004). The detailed age trajectory of oral vocabulary knowledge: Differences by class and race. Social Science Research, 33, 464-497. https://doi.org/10.1016/j.ssresearch.2003.08.001

Fernald, A., Marchman, V. A., \& Weisleder, A. (2013). SES differences in language processing skill and vocabulary are evident at 18 months. Developmental Science, 16, 234-248. https://doi.org/10.1111/desc.12019

Frankenburg, W. K., \& Coons, C. E. (1986). Home Screening Questionnaire: Its validity in assessing home environment. The Journal of pediatrics, 108, 624-626. https://doi.org/10.1016/S0022-3476\%2886\%2980853-8

Froiland, J. M., Peterson, A., \& Davison, M. L. (2013). The long-term effects of early parent involvement and parent expectation in the USA. School Psychology International, 34, 3350. https://doi.org/10.1177/0143034312454361

Ganzeboom, H. B. G., De Graaf, P. M., \& Treiman, D. J. (1992): A Standard International Socio-Economic Index of Occupational Status. Social Science Research 21, 1-56.

Ganzeboom, H. B., \& Treiman, D. J. (1996). Internationally comparable measures of occupational status for the 1988 International Standard Classification of Occupations. Social science research, 25(3), 201-239.

https://doi.org/10.1006/ssre.1996.0010 
Garg, R., Kauppi, C., Lewko, J., \& Urajnik, D. (2002). A structural model of educational aspirations. Journal of Career Development, 29, 87-108. https://doi.org/10.1177/089484530202900202

Gennetian, L. A., Magnuson, K., \& Morris, P. A. (2008). From statistical associations to causation: what developmentalists can learn from instrumental variables techniques coupled with experimental data. Developmental psychology, 44(2), 381. https://doi.org/10.1037/0012-1649.44.2.381

Guo, G., \& Harris, K. M. (2000). The mechanisms mediating the effects of poverty on children's intellectual development. Demography, 37, 431-447. https://doi.org/10.1353/dem.2000.0005

Haag, N., Kocaj, A., Jansen, M., \& Kuhl, P. (2017). Soziale Disparitäten [Social Disparities]. In P. Stanat, S. Schipolowski, C. Rjosk, S. Weirich, \& N. Haag (Eds.), IQBBildungstrend 2016. Kompetenzen in den Fächern Deutsch und Mathematik am Ende der 4. Jahrgangsstufe im zweiten Ländervergleich [IQB-trends in student achievement 2016. The second national of german and mathematics proficiencies at the end of fourth grade]. (pp. 213-236). Münster: Waxmann.

Haberman, S. J. (2009). Linking parameter estimates derived from an item response model through separate calibrations. ETS Research Report Series, 2009, i-9.

Hayes, N., Berthelsen, D. C., Nicholson, J. M., \& Walker, S. (2016). Trajectories of parental involvement in home learning activities across the early years: associations with sociodemographic characteristics and children's learning outcomes. Early Child Development and Care, 188, 1405-1418. https://doi.org/10.1080/03004430.2016.1262362

Harding, J. F., Morris, P. A., \& Hughes, D. (2015). The relationship between maternal education and children's academic outcomes: A theoretical framework. Journal of Marriage and Family, 77(1), 60-76. https://doi.org/10.1111/jomf.12156 
Hart, S. A., Soden, B., Johnson, W., Schatschneider, C., \& Taylor, J. (2013). Expanding the environment: gene× school-level SES interaction on reading comprehension. Journal of Child Psychology and Psychiatry, 54(10), 1047-1055. https://doi.org/10.1111/jcpp.12083

Hartas, D. (2011). Families' social backgrounds matter: socio-economic factors, home learning and young children's language, literacy and social outcomes. British Educational Research Journal, 37(6), 893-914. https://doi.org/10.1080/01411926.2010.506945

Hildebrandt, A., Wilhelm, O., \& Robitzsch, A. (2009). Complementary and competing factor analytic approaches for the investigation of measurement invariance. Review of Psychology, 16, 87-102.

Hildebrandt, A., Lüdtke, O., Robitzsch, A., Sommer, C., \& Wilhelm, O. (2016). Exploring factor model parameters across continuous variables with local structural equation models. Multivariate Behavioral Research, 51, 257-258. https://doi.org/10.1080/00273171.2016.1142856

Hill, N. E., \& Taylor, L. C. (2004). Parental school involvement and children's academic achievement: Pragmatics and issues. Current Directions in Psychological Science, 13, 161-164. https://doi.org/10.1111/j.0963-7214.2004.00298.x

Hoff, E. (2003). The specificity of environmental influence: Socioeconomic status affects early vocabulary development via maternal speech. Child Development, 74, 1368-1378. https://doi.org/10.1111/1467-8624.00612

Hoff, E. (2006). How social contexts support and shape language development. Developmental Review, 26, 55-88. https://doi.org/10.1016/j.dr.2005.11.002

Hoff, E. (2013). Interpreting the early language trajectories of children from low-SES and language minority homes: Implications for closing achievement gaps. Developmental Psychology, 49, 4-14. https://doi.org/10.1037/a0027238 
Hoover-Dempsey, K. V., Battiato, A. C., Walker, J.M. T., Reed, R. P., DeJong, J.M., \& Jones, K. P. (2001). Parental involvement in homework. Educ. Psychol., 36, 195-209. http://dx.doi.org/10.1207/S15326985EP3603_5.

Hoover-Dempsey, K. V., \& Sandler, H.M. (1995). Parental involvement in children's education: Why does it make a difference? Teach. Coll. Rec., 97, 310-331.

Huston, A. C., Duncan, G. J., McLoyd, V. C., Crosby, D. A., Ripke, M. N., Weisner, T. S., \& Eldred, C. A. (2005). Impacts on children of a policy to promote employment and reduce poverty for low-income parents: New hope after 5 years. Developmental Psychology, 41, 902-918. https://doi.org/10.1037/0012-1649.41.6.902

Huttenlocher, J., Waterfall, H., Vasilyeva, M., Vevea, J., \& Hedges, L. V. (2010). Sources of variability in children's language growth. Cognitive Psychology, 61, 343-365. https://doi.org/10.1016/j.cogpsych.2010.08.002

Hyde, J. S., Else-Quest, N. M., Alibali, M. W., Knuth, E., \& Romberg, T. (2006). Mathematics in the home: Homework practices and mother-child interactions doing mathematics. The Journal of Mathematical Behavior, 25, 136-152. https://doi.org/10.1016/j.jmathb.2006.02.003

International Labour Office (1990). The Revised International Standard Classification of Occupations (ISCO-88). Geneva: International Labour Office.

Kluczniok, K., \& Mudiappa, M. (2018). Relations between socio-economic risk factors, home learning environment and children's language competencies: Findings from a German study. European Educational Research Journal, 18, 85-104. https://doi.org/10.1177/1474904118790854

Krapohl, E., Rimfeld, K., Shakeshaft, N. G., Trzaskowski, M., McMillan, A., Pingault, J. B., ... \& Plomin, R. (2014). The high heritability of educational achievement reflects many genetically influenced traits, not just intelligence. Proceedings of the national academy of sciences, 111(42), 15273-15278. https://doi.org/10.1073/pnas.1408777111 
Laosa, L. (1978). Maternal teaching strategies in Chicano families of varied educational and socioeconomic levels. Child Development, 49, 1129-1135. https://doi.org/10.2307/1128752

Lee, J.-S., \& Bowen, N. K. (2006). Parent involvement, cultural capital, and the achievement gap among elementary school children. American Educational Research Journal, 43, 193-218. https://doi.org/10.3102/00028312043002193

Lee, V., \& Burkam, D. (2002). Inequality at the starting gate: Social background differences in achievement as children begin school. Washington, DC: Economic Policy Institute.

Lehrl, S., Ebert, S., Blaurock, S., Rossbach, H. G., \& Weinert, S. (2020). Long-term and domain-specific relations between the early years home learning environment and students' academic outcomes in secondary school. School Effectiveness and School Improvement, 31(1), 102-124. https://doi.org/10.1080/09243453.2019.1618346

Leventhal, T., \& Brooks-Gunn, J. (2000). The neighborhoods they live in: The effects of neighborhood residence on child and adolescent outcomes. Psychological Bulletin, 126, 309-337. https://doi.org/10.1037/0033-2909.126.2.309

Linberg, A., Attig, M., \& Weinert, S. (2020). Social disparities in the vocabulary of 2-yearold children and the mediating effect of language-stimulating interaction behavior. Journal for educational research online, 12(2), 12-35. https://doi.org/10.25656/01:20971

Lindo, E. J. (2014). Family background as a predictor of reading comprehension performance: An examination of the contributions of human, financial, and social capital. Learning and Individual Differences, 32, 287-293. https://doi.org/10.1016/j.lindif.2014.03.021

Lohndorf, R. T., Vermeer, H. J., Cárcamo, R. A., \& Mesman, J. (2018). Preschoolers' vocabulary acquisition in Chile: the roles of socioeconomic status and quality of home environment. Journal of child language, 45(3), 559-580. https://doi.org/10.1017/S0305000917000332 
McLoyd, V. C. (1998). Socioeconomic disadvantage and child development. American Psychologist, 53, 185-204. https://doi.org/10.1037/0003-066X.53.2.185

McNeal, R. B. (1999). Parental involvement as social capital: Differential effectiveness on science achievement, truancy, and dropping out. Social Forces, 78, 117-144. https://doi.org/10.1093/sf/78.1.117

Melhuish, E. C., Phan, M. B., Sylva, K., Sammons, P., Siraj-Blatchford, I., \& Taggart, B. (2008). Effects of the home learning environment and preschool center experience upon literacy and numeracy development in early primary school. Journal of Social Issues, 64, 95-114. https://doi.org/10.1111/j.1540-4560.2008.00550.x

Molenaar, D., Dolan, C. V., Wicherts, J. M., \& van der Maas, H. L.J. (2010). Modeling differentiation of cognitive abilities within the higher-order factor model using moderated factor analysis. Intelligence, 38, 611-624. https://doi.org/10.1016/j.intell.2010.09.002

Olaru, G., Schroeders, U., Hartung, J., \& Wilhelm, O. (2019). Ant colony optimization and local weighted structural equation modeling. A tutorial on novel item and person sampling procedures for personality research. European Journal of Personality, 33, 400419. https://doi.org/10.1002/per.2195

Organization for Economic Cooperation and Development. (2016). PISA 2015 results: Vol. I: Excellence and equity in education. Paris, France: Author.

Pant, H. A., Stanat, P., Schroeders, U., Roppelt, A., Siegle, T., \& Pöhlmann, C. (2013). The IQB National Assessment Study 2012: Competencies in mathematics and the sciences at the end of secondary level I. https://www.iqb.huberlin.de/bt/lv2012/Bericht/IQB_NationalAsse.pdf

Pfost, M., Dörfler, T., \& Artelt, C. (2012). Reading competence development of poor readers in a German elementary school sample: An empirical examination of the Matthew effect model. Journal of Research in Reading, 35(4), 411-426. https://doi.org/10.1111/j.1467$\underline{9817.2010 .01478 . \mathrm{x}}$ 
Pfost, M., Hattie, J., Dörfler, T., \& Artelt, C. (2014). Individual differences in reading development: A review of 25 years of empirical research on Matthew effects in reading. Review of Educational Research, 84(2), 203-244.

https://doi.org/10.3102/0034654313509492

R Core Team (2018). R: A language and environment for statistical computing. R Foundation for Statistical Computing, Vienna, Austria. URL https://www.R-project.org/.

Reardon, S. F. (2011). The widening academic-achievement gap between the rich and the poor: New evidence and possible explanations. In R. M. Murname \& G. J. Duncan (Eds.), Whither opportunity: Rising inequality, schools, and children's life chances. Washington, DC: Brookings Institute.

Rescorla, L., \& Rosenthal, A. S. (2004). Growth in standardized ability and achievement test scores from $3^{\text {rd }}$ to $10^{\text {th }}$ grade. Journal of Educational Psychology, 96(1), 85-96. https://doi.org/10.1037/0022-0663.96.1.85

Revelle, W. (2020) psych: Procedures for Personality and Psychological Research, Northwestern University, Evanston, Illinois, USA, https://CRAN.Rproject.org/package $=$ psych Version $=2.0 .8$.

Rjosk, C., Haag, N., Heppt, B., \& Stanat, P. (2017). Zuwanderungsbezogene Disparitäten [Imigration-related disparities]. In P. Stanat, S. Schipolowski, C. Rjosk, S. Weirich, \& N. Haag (Eds.), IQB-Bildungstrend 2016. Kompetenzen in den Fächern Deutsch und Mathematik am Ende der 4. Jahrgangsstufe im zweiten Ländervergleich [IQB-trends in student achievement 2016. The second national of german and mathematics proficiencies at the end of fourth grade] (S. 237-275). Münster: Waxmann.

Roberts, E., Bornstein, M. H., Slater, A. M., \& Barrett, J. (1999), Early cognitive development and parental education. Infant and Child Development, 8, 49-62. https://doi.org/10.1002/(SICI)1522-7219(199903)8:1<49::AID-ICD188>3.0.CO;2-1 
Robitzsch, A. (2019). sirt: Supplementary Item Response Theory Models. R package version

\section{6-21. https://CRAN.R-project.org/package=sirt}

Robitzsch, A., Kiefer, T., \& Wu, M. (2019). TAM: Test analysis modules. R package version

\section{2-24. https://CRAN.R-project.org/package=TAM}

Rosseel, Y. (2012). lavaan: An R Package for Structural Equation Modeling. Journal of Statistical Software, 48, 1-36. https://doi.org/10.18637/jss.v048.i02

Rowe, D. C., Jacobson, K. C., \& Van den Oord, E. J. (1999). Genetic and environmental influences on vocabulary IQ: Parental education level as moderator. Child Development, 70(5), 1151-1162. https://doi.org/10.1111/1467-8624.00084

Roßbach, H.-G., Tietze, W., \& Weinert, S. (2005): Peabody picture vocabulary test revised. Deutsche Forschungsversion des Tests von L. M. Dunn \& L. M. Dunn von 1981 [Peabody picture vocabulary test revised. German research version of the test from L. M. Dunn \& L. M. Dunn von 1981]. Universität Bamberg, Freie Universität Berlin

Rowe, M. L. (2008). Child-directed speech: Relation to socioeconomic status, knowledge of child development and child vocabulary skill. Journal of Child Language, 35, 185-205. https://doi.org/10.1017/S0305000907008343

Rowe, M. L., \& Goldin-Meadow, S. (2009). Differences in early gesture explain SES disparities in child vocabulary size at school entry. Science, 323, 951-953. https://doi.org/10.1126/science.1167025

Rutkowski, D., \& Rutkowski, L. (2013). Measuring socioeconomic background in PISA: One size might not fit all. Research in Comparative and International Education, 8(3), 259278. https://doi.org/10.2304/rcie.2013.8.3.259

Scarborough, H. S., \& Dobrich, W. (1994). On the efficacy of reading to preschoolers. Developmental Review, 14, 245-302. https://doi.org/10.1006/drev.1994.1010 
Schroeders, U. (2018). Ability. In M. H. Bornstein (Ed.), The SAGE Encyclopedia of Lifespan Human Development (pp. 1-5). Thousand Oaks, CA: SAGE Publications, Inc. https://doi.org/10.4135/9781506307633.n8

Sénéchal, M. (2006). Testing the home literacy model: Parent involvement in nursery school is differentially related to grade 4 reading comprehension, fluency, spelling, and reading for pleasure. Scientific Studies of Reading, 10, 59-87. https://doi.org/10.1207/s1532799xssr1001_4

Snow, R. E. (1989). Aptitude, instruction, and individual development. International Journal of Educational Research, 13, 869-881. https://doi.org/10.1016/0883-0355(89)90070-0

Sohr-Preston, S. L., Scaramella, L. V., Martin, M. J., Neppl, T. K., Ontai, L., \& Conger, R. (2013). Parental socioeconomic status, communication, and children's vocabulary development: A third-generation test of the family investment model. Child Development, 84, 1046-1062. https://doi.org/10.1111/cdev.12023

Tarelli, I., \& Stubbe, T. C. (2010). Home Literacy Environment and Reading Achievement : A Model for Determining the Relationship between Socio-Economic Status, Home Literacy Environment and Reading Achievement; In 4th International Research Congress of IEA. Retrieved from https://www.iea.nl/sites/default/files/201904/IRC2010_Tarelli_Stubbe.pdf

UNESCO Institute for Statistics (2011). International Classification of Education (ISCED) 2011, Montreal, Canada: Retrieved from http://www.uis.unesco.org/Education/Documents/isced-2011-en.pdf van Steensel, R. (2006). Relations between socio-cultural factors, the home literacy environment and children's literacy development in the first years of primary education. Journal of Research in Reading, 29, 367-382. https://doi.org/10.1111/j.1467$\underline{9817.2006 .00301 . x}$ 
Volodina, A., Weinert, S., \& Mursin, K. (2020). Development of academic vocabulary across primary school age: Differential growth and influential factors for German monolinguals and language minority learners. Developmental psychology, 56(5), 922. https://doi.org/10.1037/dev0000910

Watermann, R., \& Baumert, J. (2006). Entwicklung eines Strukturmodells zum Zusammenhang zwischen sozialer Herkunft und fachlichen und überfachlichen Kompetenzen [Development of a structural model of the association between family background and curricular and cross-curricular competencies]. In J. Baumert, P. Stanat, \& R. Watermann (Eds.), Herkunftsbedingte Disparitäten im Bildungswesen: Differenzielle Bildungsprozesse und Probleme der Verteilungsgerechtigkeit (pp. 61-94). Wiesbaden: VS Verlag für Sozialwissenschaften

Weinert, S., \& Ebert, S. (2013). Spracherwerb im Vorschulalter: Soziale Disparitäten und Einflussvariablen auf den Grammatikerwerb [Language development in the pre-school age: Social disparities and effects on the acquisition of grammar]. Zeitschrift für Erziehungswissenschaft, 16, 303-332. http://dx.doi.org/10.1007/s11618-013-0354-8 